\title{
INTERPRETANTES DINÂMICOS DE ESTUDANTES DAS RELAÇÕES DOS ANIMAIS HUMANOS E NÃO HUMANOS: UMA LEITURA PEIRCEANA A PARTIR DE UMA INTERVENÇÃO DIDÁTICA
}

\author{
STUDENTS DYNAMIC INTERPRETERS OF HUMAN AND NON-HUMAN \\ ANIMALS RELATIONS: \\ A PEIRCEAN READING FROM A DIDACTIC INTERVENTION
}

A grandeza de uma nação pode ser julgada pela maneira como seus animais são tratados (Mahatma Gandhi)

\author{
Adriana Ribeiro Ferreira Rodrigues ${ }^{1}$ \\ Carlos Eduardo Laburu ${ }^{2}$ \\ Osmar Henrique Moura da Silva ${ }^{3}$
}

\section{RESUMO}

O presente trabalho apresenta perspectivas de estudantes quanto às formas de relação dos seres humanos com os animais, no contexto da disciplina de Biologia no segundo ano do ensino médio. Por meio de uma intervenção didática que abordou os conteúdos de animais vertebrados segundo um enfoque relacional e de discussão de tais formas de relação, foram produzidas informações baseadas em uma leitura da tríade dos interpretantes dinâmicos de Peirce gerados pelos estudantes. Dentro desse referencial semiótico, observou-se ser possível discriminar os interpretantes emocional, energético e Lógico e que os mesmos se estruturaram distintamente do interpretante dinâmico inicial possuído pelos aprendizes após intervenção didática.

Palavras-chave: ensino, Peirce, interpretantes dinâmicos, relações humanos e animais, biologia.

\footnotetext{
${ }^{1}$ Docente da Rede pública de Ensino do Estado do Paraná. Ponta Grossa, PR, Brasil. E-mail: adrianarfr@yahoo.com.br

${ }^{2}$ Departamento de Física, Universidade Estadual de Londrina (UEL), caixa postal 6001, CEP 86051-970, Londrina, PR, Brasil. E-mail: laburu@uel.br, Bolsista CNPq (proc.: 302281/2015-0).

${ }^{3}$ Departamento de Física, Universidade Estadual de Londrina (UEL), caixa postal 6001, CEP 86051-970, Londrina, PR, Brasil. E-mail: laburu@uel.br, Bolsista CNPq (proc.: 302281/2015-0).
} 


\section{ABSTRACT}

This work presents students' perspectives on the relationship between human beings and animals, in the context of biology in the second year of high school. Through a didactic intervention that approached the contents of vertebrate animals according to a relational approach and discussion of such forms of relation, information was produced based on a reading of peirce triad dynamic interpreters generated by the students. Within this semiotic referential, it was observed that it was possible to discriminate the emotional, energetic and logical interpreters and that they were structured distinctly from the initial dynamic interpretant possessed by the apprentices after didactic intervention.

Keywords: teaching, Peirce, dynamic interpreters, human and animal relations, biology.

\section{INTRODUÇÃO}

A Educação Ambiental é essencialmente um processo para fornecer condições para a educação e a participação de cidadãos capazes de assumir a responsabilidade pela formação e a gestão de seus próprios ambientes (HART, 2012), em que problematizar as formas de relação dos animais humanos e não humanos integra o corpo de conhecimentos necessários ao sujeito ambientalmente educado. Refletir acerca disso implica trazer à tona como se dão tais formas de relação como pressuposto necessário para integrar uma Educação Ambiental crítica e um ensino de Biologia contextualizado e significativo, que questione esses modelos (FERREIRA \& LABURÚ, 2017a). Falar das relações dos humanos com os animais e, num sentido mais amplo, das relações com a natureza, constitui tema multidimensional formado por valores e interesses humanos, questões éticas, políticas, filosóficas e, portanto, socialmente construído e conflituoso (LEFF, 2001, 2003; REIGOTA, 2001a, 2001b). Nesse contexto, o ensino de conceitos associados aos grupos de animais vertebrados vê-se apropriado para possibilitar ampliar esse conhecimento aos aspectos relacionais de tais conteúdos (FERREIRA \& LABURÚ, 2017b). Tomando por base uma leitura dos conceitos da semiótica de Peirce (1978, 1989), no presente estudo busca-se obter a qualidade das distintas formas de relação dos seres humanos com os animais não humanos à 
luz da tríade interpretante dinâmica emocional, energética e lógica, gerada quando de uma intervenção didática.

Investigam-se aqui esses interpretantes de alunos do ensino médio, apropriados a partir de distintos signos utilizados durante a instrução dos conteúdos das Classes de animais vertebrados. Para isso, o trabalho apresenta a gama de entendimentos dos estudantes acerca das relações dos seres humanos com os animais como signos produtores de interpretantes no contexto de um ensino dos conteúdos sobre vertebrados com abordagem ambiental, dentro do ensino de Biologia. O estudo mostra o aumento da complexidade da compreensão dos estudantes a respeito das relações animais humanos e não humanos, auxiliado pelo instrumento analítico dos interpretantes emocional, energético e lógico, conforme o referencial semiótico mencionado.

\section{OS INTERPRETANTES NA SEMIÓTICA PEIRCEANA}

A semiótica é parte integrante do sistema filosófico de Peirce, fundada no pragmatismo. É uma ponte filosófica possível para acessarmos os significados produzidos pelos sujeitos cognoscentes nos processos comunicativos e para elencarmos evidências da semioses, que quer dizer ações dos signos, como aprendizagem por meio da identificação dos interpretantes.

O pragmatismo é fundamentalmente uma teoria do conhecimento que visa dar resposta à pergunta "Como se dá o conhecimento?" (SHOOK, 2002, p. 11). Uma das preocupações do pragmatismo é a busca pelas verdades temporais, e não absolutas, sendo verdades que servem para um determinado tempo e situação. Defende que é possível aumentar a experiência e o conhecimento humano num constante processo, já que somos parte de uma rede de conhecimento muito maior do que aquilo que conhecemos. Uma experiência que não se dá somente no plano concreto material, mas nos aspectos sociais e morais. 
A semiótica peirceana, preconizada como a ciência geral dos signos, buscou entender 0 mundo da existência humana e garantir sua comunicabilidade. (FIDALGO; GRANDIM, 2005). Pensamos por meio de signos e, assim, todo signo significa algo, sendo que o grande desafio é saber o que e para quem significa. Por meio do signo, é possível que algo exterior seja comunicado à mente (PEIRCE apud SANTAELLA, 2008, p. 12,18).

O caráter vicário do signo refere-se à sua capacidade de mediar o objeto e a mente, ou seja, estar no lugar de alguma coisa (SANTAELLA, 2008; FIDALGO; GRANDIM, 2005). Na acepção peirceana, o modo de funcionamento do signo compõe-se de três elementos: aquilo que atua como signo (representamen), que é o primeiro correlato, aquilo a que o signo se refere (objeto), que é o segundo correlato, e o efeito sobre um intérprete (interpretante), que é o terceiro correlato. Em relação ao conceito de interpretante, uma das partes que constitui o signo, e dentre todos os correlatos, é o mais associado à semiose, podendo reproduzir-se ad infinitum.

Peirce define interpretante de diversas formas, dentre elas, que o "signo cria algo na mente do Intérprete, algo esse que foi também, de maneira relativa e mediada, criado pelo Objeto do Signo, embora o Objeto seja essencialmente diverso do Signo. Ora, esta criatura do Signo chama-se Interpretante" (PEIRCE, 1978 e 1989).

O interpretante é uma característica intrínseca do signo, ou seja, é um conteúdo objeto do signo com capacidade de produzir um interpretante na mente do intérprete. Santaella (2008, p. 63) ressalva que "a noção de interpretante não significa, porém, que não existem atos interpretativos particulares e individuais". Estes podem ocorrer quando os signos em questão se deparam com a mente do intérprete em todas as suas singularidades e experiências pessoais.

Uma característica do interpretante é tornar-se ele próprio outro signo, e desencadear uma nova semiose. Nessa semiose ilimitada, derivada de uma sucessão de pensamentos que geram novos signos, ocorre a construção de significados na mente do intérprete, algo absolutamente desejável num 
processo de formação científica e ambiental como forma de constituir o cerne da formação do pensamento crítico, que não fica estagnado.

Os interpretantes peirceanos estão classificados em imediato, dinâmico e final. Santaella (2008, p. 67) comenta que "esta divisão diz respeito aos níveis por que passa o interpretante até se converter em outro signo, caminhando para o interpretante em si ou interpretante final".

O interpretante imediato é identificado como o efeito imediatamente produzido pelo signo e que não teve qualquer tipo de análise ou reflexão, relaciona-se à qualidade de impressão que um signo está apto a produzir. É um interpretante interno ao signo e poderia neste contexto ser analisado com relação ao conteúdo implícito, próprio de cada signo utilizado. É o interpretante que "seria" se houvesse um intérprete (PEIRCE, 2012, p. 493). Já o interpretante dinâmico refere-se ao efeito efetivamente produzido pelo signo. "Corresponde à interpretação atual de qualquer signo, é uma ocorrência, pode diferir para cada intérprete do signo" (GRANDIM e FIDALGO, 2005, p. 154). Como interpretação particular do signo, a variação de sentidos para cada intérprete irá proporcionar uma riqueza de ideias. É a interpretação concreta do signo que, conforme afirma Santaella (2008, p. 73), é "o único interpretante que funciona diretamente num processo comunicativo", algo que se efetiva numa sala de aula, por exemplo. Por sua vez, o interpretante final refere-se ao resultado interpretativo derivado de um processo no qual o signo pudesse ser levado ao extremo da sua consideração e atuaria na formação do hábito e do autocontrole deliberado. Peirce $(1978,1989)$ diz que o interpretante final não consiste na ação atual da mente, mas na forma em que cada mente agiria numa situação futura. Assim, o interpretante final está ligado àquilo para o qual a realidade tende, é um ideal a ser alcançado.

Particularmente, o interpretante dinâmico pode produzir três tipos de efeito no intérprete, a saber: interpretante emocional; interpretante energético ; interpretante lógico. Enquanto o primeiro sensibiliza, desestabiliza, o segundo move para a ação consciente e o terceiro sistematiza o pensamento. 0 interpretante dinâmico caracteriza-se como acontecimento, concretude, e para 
Santaella (2008, p. 73) "é o efeito efetivamente produzido pelo signo num ato de interpretação concreto e singular", e não apenas potencialidade.

O interpretante dinâmico emocional "é o primeiro efeito semiótico, em termos de qualidade, portanto, qualidade de sentimento de um signo" (SANTAELLA, 2008, p. 78). Porém, Peirce salienta que este interpretante pode ser mais do que o sentimento de reconhecimento e em alguns casos é o único efeito que o signo produz. Dele se apresenta um sentido mais vago e indefinido, que diz respeito a uma qualidade de sentimento inanalisável e intraduzível (SANTAELLA, 2008, p. 79). Ao considerar esse efeito interpretante num processo de ensino e aprendizagem, vale ressaltarmos a importância das emoções.

Cabe esclarecer, que do ponto de vista da leitura que aqui se está fazendo de Peirce, o interpretante emocional é o efeito interpretante produzido pelo signo que está por detrás de um conteúdo específico. Isto significa dizer que ele precisa ser compreendido a partir do enquadramento do conteúdo em foco, em vez de genéricos estados de sentimento ou disposição psíquica de emoção, afetividade, desejo, motivação, ansiedade, vontade de estudar, crença de auto eficácia etc. Quando tais qualidades não permanecem circunscritas a fatores de ordem exclusivamente psicológicas, mas provocadas pelo que o signo significa para o sujeito, com consequente interferência cognitiva ligada ao conteúdo, a esse interpretante são genuinamente atribuídas essas qualidades.

O interpretante dinâmico energético produz um efeito sempre como um esforço, muscular ou mental, mas geralmente, um esforço sobre o mundo interior, um esforço mental (PEIRCE,1978, 1989). Segundo Savan (apud SANTAELLA, 2008, p. 79), "os objetos físicos que agem sobre nós e sobre os quais agimos têm uma auto identidade que independe de nós, oferecendo resistência às nossas manipulações". Justamente por isso, requer que empreendamos algum esforço muscular ou mental na sua direção, como um interrogatório que se faz a si mesmo na busca de respostas.

O Interpretante energético, na leitura que empreendemos, é o efeito significado revelador da qualidade ou disposição da apreensão conceitual demonstrada através de atos concretos de interpretação, levando a ou 
traduzindo-se em "esforços musculares". No nível energético, a ação física, reflexo de uma ação interiorizada, toma parte integrante do efeito significado. Do ponto de vista dessa ação, são traduzíveis comportamentos, atitudes, procedimentos e técnicas originados do processo educacional, ainda que estes se apresentem de início um tanto quanto metódicos, mecânicos ou estritamente fixos. Sua correspondência com o hábito, ato ou manipulação leva a resposta comportamental despender alguma energia em relação ou reação ao mundo tanto material como social. Da reação originada da auto identidade particular das distintas situações que agem sobre nós e sobre as quais agimos ou influenciamos, oferecendo, muitas vezes, resistência às manipulações, surge a necessidade, frente aos novos fatos, de criar atos, hábitos ou comportamentos sociais novos.

O interpretante lógico "é o pensamento ou entendimento geral produzido pelo signo" (SANTAELLA, 2008, p. 79) a partir do qual o intérprete, utilizandose de novas regras internalizadas, faz novas relações e atualiza o signo. Porém, Peirce $(1978,1989)$ adverte que "não se deve supor que cada vez que se apresenta um signo capaz de produzir um interpretante lógico, tal interpretante se produza realmente".

A leitura que damos para esse interpretante lógico aponta para o efeito significado, este expresso junto aos signos comunicativos em meio a regras interpretativas formais e normativas, cujo foco é o conteúdo conceitual. Esse efeito interpretante se dá por função semântica e base sintática, estando associado aos modos de expressão, significado e sentido dos termos, símbolos e referências utilizados pela nova concepção. Com ele se permite construir e identificar representações, ideias e proposições coerentes, internamente consistentes e inter-relacionadas. O signo é interpretado por meio do domínio de novas regras internalizadas pelo intérprete que auxiliam a fazer inferências e estabelecer consequências de premissas. Tais regras, de natureza associativa, conectam o signo a outros objetos e signos do conhecimento de maneira unívoca, sem admissibilidade de equívoco.

A partir do interpretante lógico resulta outro lógico, assim, Peirce considera que é necessário que esse interpretante lógico último não seja um 
signo ou conceito, mas sim da natureza de conduta, ou seja, de hábitos que alterem as tendências de ação de uma pessoa. Por meio do interpretante lógico como hábito é possível conduzir o pensamento para a ação deliberada. Contudo, Santaella (2004) adverte que um interpretante lógico como hábito não significa uma definitiva inflexibilidade, mas atuar apenas como um condutor para as nossas ações e novos hábitos por abandono dos antigos (ibid., p. 82).

\section{INTERPRETANTES DINÂMICOS E O APRENDIZADO ACERCA DAS RELAÇÕES DOS SERES HUMANOS COM OS ANIMAIS NÃO HUMANOS}

As relações seres humanos e natureza são mediadas por relações socioculturais. Vivemos nossa vida com os animais não humanos. Esse é um ponto de partida factual e incontestável. Eles estão ao nosso redor, fisicamente, simbolicamente, sensivelmente nos provocando a lembrança de que somos animais também. Assim, como animais humanos somos uma extensão dos não humanos.

Neste sentido, questionar a identidade humana em relação à identidade não humana implica considerá-los como outro. Ao pensar esse "outro", Souza (2007, p. 124, grifo nosso), quando discute a ética da Alteridade a partir de Emmanuel Levinas, questiona: "Quem tem sido os animais ao longo da história do poder humano?' Parece que os animais não têm podido ser. Estão expostos à exploração, ao uso, ao maltrato provocado pelos seres humanos.

Se o que se almeja é uma relação de forma solidária, justa, de respeito e a favor de todas as formas de vida, a visão dos animais como "outro" não pode ser ignorada. $E$ os mesmos princípios são a iniciação para que os humanos respeitem-se entre si. Em outras palavras, só será possível compreendê-las nas singularidades da sua existência, colocando-nos no seu lugar e sentindo as consequências das agressões que sofrem. O sentido do "valor" da existência dos animais não humanos no contexto da vida humana é alterado quando estes passam a ser vistos como coisas de utilidade, quando seus corpos são considerados como mercadorias capazes de serem convertidos em dinheiro. 
Essa relação coisificada ausente de compaixão ou empatia pelo outro que é senciente, ou seja, que sente e sofre, desconsidera a alteridade.

Pensar em uma proposta educativa a ser desenvolvida na escola, a fim de questionar as formas de relação dos seres humanos com os animais, precisa assegurar o entendimento de que os animais não humanos devem ser também sujeitos de consideração no processo de estudo, não são coisas, mas sujeitos de uma vida. Aprender sobre eles significa inclusive colocar em questão a forma como foram estudados ao longo da história da humanidade. Para Brügger (2009), a cultura humana não ambiental, como já apontamos anteriormente, tem ao longo da história influenciado nossas formas de relação com a natureza, manifestando como característica mais evidente o antropocentrismo. A superação desse modelo antropocêntrico, passando a outro não antropocêntrico, requer uma proposta de Educação Ambiental que enfatize "em menor ou maior grau valores biocêntricos, ecocêntricos e zoocêntricos" (ibid., p. 201). A superação desse modelo, para Brügger (ibid.), passa pelo questionamento da inclusão dos animais não humanos na comunidade moral e da superação do especismo, ou seja, haver preocupação com os animais em extinção ou selvagens, mas não somente com os domésticos ou os de laboratório.

No contexto dessa temática, a educação não pode ignorar os entrelaçamentos entre a razão e a emoção. O sistema racional passa sim por um fundamento emocional, seja ele qual for, bom ou ruim, pois a ética não tem fundamento racional, mas sim emocional. E aí se insere a possibilidade de ensinar a sentir e pensar novas perspectivas a partir de um debate racional e responsável para com o ambiente e todas as formas de vida. Anderson (2004) traz interessantes discussões no âmbito das contribuições do pragmatismo norte americano e mais especificamente do pragmatismo animal, para as discussões sobre animais humanos e não humanos. No artigo intitulado "Peirce's Horse: A Sympathetic and Semiotic Bond", o autor (ibid.) revela de forma pertinente como os animais não humanos aparecem na obra de Peirce. Ele adverte que tal obra não é exatamente o primeiro lugar onde deveríamos

\footnotetext{
${ }^{4} \mathrm{O}$ cavalo de Peirce: uma amizade e um vínculo semiótico.
} 
buscar essa discussão. Porém, algumas características de transcendentalismo no trabalho de Peirce possibilitam entender alguns aspectos das nossas relações com os animais não humanos em uma perspectiva peirceana.

A conduta da convivência a partir dos pressupostos da ética de Peirce nos permite pensar que é necessário reconhecer as diferenças intrínsecas às existências humanas e não humanas. Assim, precisamos de uma educação científica, e/ou um ensino de Biologia, e/ou uma Educação Ambiental que permita discutir as relações animais e humanos a partir da alteridade, reconhecendo as diferenças e exercitando a capacidade de colocar-se em seu lugar, a fim de compreender os impactos das ações humanas na existência dos animais não humanos.

Aprender mais sobre a vida dos outros animais é uma investigação
científica. E a teoria de tal investigação é o cerne da lógica, que,
juntamente com a estética e ética, constitui uma ciência normativa. A
primeira questão normativa nas nossas relações com os animais,
portanto, ocorre quando perguntamos como devemos estudá-los. Isto
é, não são formas adequadas ou inadequadas para prosseguir a
investigação e, assim, perseguindo o conhecimento dos animais. [...]
Qualquer que seja o estudo que realizamos, comportamental ou
fisiológico, para aprender sobre os animais (ou pessoas), deve ser
iniciado por uma análise lógica fenomenológica das suas vidas. Isso,
como sabemos, requer percepção atenta e uma apreensão simpática
da vida animal. (ANDERSON, 2004, p. 91)

Em uma Educação Ambiental que visa modificar as formas de relação dos animais humanos com os animais não humanos, ou com a natureza de forma ampla, o alvo do processo semiótico seria chegar a um interpretante lógico como hábito. E a corporificação do signo por meio de ações, hábitos e mudanças de hábitos produzidas no intérprete o levaria à liberdade de adotar a ação deliberada e de incorporar um padrão de ação desejável para um sujeito ambientalmente educado. Aqui, o hábito peirceano difere da noção mais geral de hábito como comportamento condicionado. Para Peirce, o hábito não é algo rígido, de repetição impensada, mas sim um princípio guia, de continuidade, flexível, e que pode ser rompido em algum momento (SANTAELLA, 2004).

Fidalgo e Grandim (2005), ao discutirem acerca da noção de interpretante, afirmam que "qualquer signo produzido e usado por um intérprete pode também servir para obter informações sobre esse intérprete" (ibid., p. 101). Ao utilizarmos signos que geram interpretantes, é possível acessarmos 
os conteúdos deles resultantes como formas de promover a formação ambiental adequada por meio da discussão desses conteúdos, que colocará em questão os modos de pensar dos aprendizes intérpretes. Desse modo, os signos adquirem um carácter diagnóstico, sendo "perfeitamente legítimo para certos fins utilizar signos simplesmente em ordem a produzir certos processos de interpretação" (ibid., p. 101) que irão nos possibilitar observar evidências do aprendizado, ou seja, quando a semiose propicia a cognição.

Nos processos de ensino aprendizagem, na maioria das vezes o contato com o objeto se dá no nível da representação e não da apresentação. Assim, a experiência será relevante no processo de semiose, pois irá mobilizar a memória, o vivido pelo intérprete no âmbito da sua vida pessoal e coletiva. A experiência de senso comum é composta de forma bastante diversa por todas as formas de comunicação que atingem as pessoas cotidianamente. Os animais não humanos estão presentes na nossa vida pela convivência doméstica com animais de estimação, pela publicidade, pelas lojas que comercializam animais, pela programação da televisão, pela internet, pelos celulares constantemente conectados, pela rápida disseminação de vídeos e imagens via dispositivos móveis, pelas experiências de aprendizado na escola, pela sua alimentação, vestuário, diversão, etc. As reportagens dos telejornais envolvendo maus tratos ou exemplos de solidariedade para com os animais não humanos, os alimentos de origem animal no nosso prato, os calçados e produtos fabricados a partir de animais, são experiências que expõem as pessoas às diversas formas com que os animais não humanos são representados na sociedade humana. Assim, por mais que tais relações não tenham sido discutidas e problematizadas, elas integram de alguma forma a experiência do senso comum de alunos e alunas.

Portanto, temos dois momentos ou gradações da experiência do senso comum no decorrer de um processo de ensino e aprendizagem que trate das relações dos animais humanos e não humanos, uma primeira, advinda das situações expostas acima, e uma segunda, derivada do aprimoramento ou da ressignificação do signo por meio da leitura, debate, estudo, que permitirá a atualização do signo e propiciará novas semioses. Além disso, para Peirce, o 
hábito e a crença não são alterados apenas por meio de uma interpelação teórica diante do sujeito. Para que se alterem, é necessária uma outra experiência que mude a crença e, por extensão, o hábito.

No sentido da educação pragmatista, discutida por Turrisi (2002), a exposição à experiência é o principal apoio do processo de ensino, independentemente do conteúdo. Entendendo que a aprendizagem pode ser arbitrada pelo professor, somente a exposição e o mergulho na experiência poderão aproximar o aprendiz da complexidade dessa realidade e, assim, ele poderá aprender. Quando o indivíduo atua sobre algo, ele articula e se expressa, cobre lacunas que a palavra não pode expressar. Agir fortalece a cognição, e os interpretantes são fortalecidos. Trazer os interpretantes à tona possibilita a tomada de consciência de seus conteúdos para que a ação deliberada ganhe espaço.

\section{METODOLOGIA}

A opção metodológica deste trabalho se fundamenta na pesquisa qualitativa, conforme proposto por Chizzotti (2003, p. 221) definindo-a no sentido de "uma partilha densa com pessoas, fatos e locais que constituem objetos de pesquisa, para extrair desse convívio os significados vivíveis e latentes que somente são perceptíveis a uma atenção sensível'. O problema de pesquisa aqui investigado está atrelado a um processo de intervenção didática. Esta se referiu às aulas regulares dos conteúdos sobre animais vertebrados previstos no plano de trabalho docente para o ano letivo em que elaboramos um material, destinado especificamente para este fim. Tal material, composto dos temas biológicos e ambientais propostos para cada classe de vertebrados contaram com vídeos didáticos, documentários, textos científicos, imagens e modelos 3D. A pesquisa empírica se deu no contexto de uma sala de aula de uma escola pública de uma região de periferia do município de Ponta Grossa - PR, numa turma de trinta e dois alunos do segundo ano do Ensino Médio noturno, disciplina de Biologia. Desta turma, a amostra aqui investigada ficou composta por treze estudantes, em função da 
regularidade das participações em todas as atividades propostas ao longo da intervenção didática. Por uma questão ética, os treze estudantes ficaram identificados por uma trinca de letras para preservar o anonimato dos mesmos.

Durante a estratégia didática, dentre os distintos elementos para a produção dos dados da pesquisa, as narrativas foram registros escritos elaborados pelos alunos e alunas acerca do tema "Relações dos seres humanos com os animais" antes e depois da intervenção didática. Esta intervenção didática foi defendida noutro trabalho (FERREIRA \& LABURÚ, 2017b), em que os modos específicos utilizados para desenvolver os conteúdos de animais vertebrados na referida turma seguem apresentados no quadro 1.

Quadro 1: Modo representacional utilizado para as atividades da intervenção didática

\begin{tabular}{|l|l|}
\hline Atividade & Modo \\
\hline Texto didático científico & Verbal-textual \\
\hline $\begin{array}{l}\text { Exposição oral, discussões, slides com } \\
\text { imagens e textos }\end{array}$ & Verbal oral, textual imagético \\
\hline Construção de modelos 3D de imagens e & $\begin{array}{l}\text { Verbal-textual, verbal - } \\
\text { imagético }\end{array}$ \\
\hline $\begin{array}{l}\text { Visualização e discussão de } \\
\text { vídeos }\end{array}$ & Verbal-textual \\
\hline Produção de narrativas & Verbal textual, verbal - oral \\
\hline Leitura e debate de texto didático científico & Verbal imagético \\
\hline Produção de curta metragens & Imagético \\
\hline Desenhos &
\end{tabular}

Fonte: Ferreira e Laburú (2017b).

Particularmente a cada uma das atividades realizadas, esses modos representacionais relacionados podem ser assim descritos: a) Modo representacional imagético - nesse modo foram utilizadas imagens de animais nos slides das aulas e os dois documentários exibidos. Nas atividades que envolveram esse modo representacional, os alunos e alunas foram orientados a atentar-se para as exibições, pois em seguida deveriam elaborar uma narrativa sobre o documentário para posterior discussão. Quanto ao material imagético dos conteúdos biológicos, eles serviriam de referência para a elaboração do modelo 3D de um representante de cada classe de vertebrados; 
b) Modo representacional verbal-textual - relaciona-se a três situações distintas quando foram utilizados textos para a leitura acerca dos peixes, anfíbios, répteis e mamíferos. Houve a produção textual dos alunos e alunas na forma de narrativas, no início da intervenção didática, após a exibição de cada documentário e ao final das atividades. Também a descrição textual do desenho prévio e do modelo 3D elaborado para cada classe; c) Modo representacional verbal-oral - refere-se às argumentações orais ocorridas durante a intervenção didática, durante as aulas relacionadas aos conteúdos biológicos das classes de vertebrados, após a leitura dos textos, após a elaboração das narrativas dos documentários e na entrevista final. Todos os estudantes tiveram diversas e distintas oportunidades de se expressar e elaborar argumentos acerca dos temas discutidos; d) Modo representacional tridimensional imagético - elaboração de modelos 3D de um representante de cada classe de vertebrados e descrição textual do modelo por meio de um esquema de questões acerca da classe. (FERREIRA \& LABURÚ, 2017b).

Para a análise, utilizamos restritamente da leitura dos interpretantes dinâmicos peirceanos mencionados em seção anterior e que propicia observar evidências da semiose como cognição que atualiza os signos, amplia a experiência do senso comum e contribui como um passo para a formação de um potencial idealizado interpretante final como hábito, algo desejável para uma Educação Ambiental biocêntrica.

Tomando como base os interpretantes dinâmicos emocional, energético e lógico, o quadro 2 abaixo exibe a matriz de referência usada como instrumento analítico para o exame dos dados.

Quadro 2: Matriz de referência para identificação dos interpretantes

\begin{tabular}{|l|l|}
\hline Interpretante & Critérios de identificação \\
\hline Emocional & $\begin{array}{l}\text { Presença de verbos, palavras, expressões que evocam } \\
\text { qualidade de sentimento, emoções, na escrita ou na fala de }\end{array}$ \\
\hline
\end{tabular}




\begin{tabular}{|l|l|}
\hline \multirow{5}{*}{ Energético } & $\begin{array}{l}\text { alunos e alunas acerca dos signos associados aos animais } \\
\text { humanos e não humanos. Manifestações e expressões faciais, } \\
\text { verbalizações de recusa, repulsa, solidariedade, compaixão, } \\
\text { empatia, simpatia. }\end{array}$ \\
\hline & $\begin{array}{l}\text { Presença de verbos, palavras, expressões que evocam } \\
\text { qualidade de ação, conflito de ideias, esforço de } \\
\text { entendimento, dúvida, questionamento, prescrições, } \\
\text { indicações imperativas, sugestões, necessidade de } \\
\text { posicionamento na escrita ou na fala acerca dos signos } \\
\text { associados aos animais humanos e não humanos. Diálogos, } \\
\text { observações do entorno, posicionamento na compra ou na } \\
\text { venda de produtos, socialização das informações com outros } \\
\text { sujeitos fora da escola, olhar atento para o entorno, para } \\
\text { registro fotográfico e fílmico. }\end{array}$ \\
\hline $\begin{array}{l}\text { Lresença de verbos, palavras, expressões que evocam } \\
\text { qualidade de interpretação, de regras gerais, de } \\
\text { posicionamento diante de um fato ou ideia, argumento acerca } \\
\text { da sua concordância ou discordância diante de um fato ou } \\
\text { ideia, na escrita ou na fala acerca dos signos associados aos } \\
\text { animais humanos e não humanos. Posicionamentos } \\
\text { argumentados, mudança de conduta. }\end{array}$ \\
\hline
\end{tabular}

Fonte: Ferreira e Laburú (2017b), adaptado de Brando e Caldeira (2009); Rosa-Silva (2013).

As análises se deram em dois momentos denominados de Narrativas inicial e final. No momento Narrativa inicial, buscamos identificar os três efeitos interpretantes a partir do texto produzido pelos estudantes no primeiro dia da intervenção didática, captando os interpretantes dinâmicos produzidos e que ainda não haviam sido influenciados pela experiência da instrução no decorrer das aulas. No momento da Narrativa Final, empreendemos o mesmo movimento de identificação dos interpretantes dinâmicos, porém, as narrativas elaboradas ao final do processo traduziram os efeitos interpretantes já influenciados pela experiência vivenciada ao longo do processo da intervenção didática.

Para as narrativas inicial e final, a frase geradora da conversação professor/estudantes ("Fale sobre os animais. E os animais em relação aos seres humanos") atuou como signo complexo, com potencial de estimular significados na mente dos intérpretes, mediante semiose do representamen com interpretantes dinâmicos. Os alunos e alunas que reagiram a esse signo, o 
expressaram no modo de representação escrito e oral, de onde os interpretantes produzidos pelo mesmo foram obtidos.

No momento da narrativa inicial, os estudantes foram solicitados a discorrer sobre a frase acima citada, e a partir do texto produzido por eles, foram identificados os três tipos de interpretantes dinâmicos.

No momento da narrativa final foram produzidas textos pelos estudantes após o processo de intervenção didática. Nesta intervenção ocorreram leituras que propunham a reflexão sobre as formas de relação dos seres humanos com os animais não humanos, as singularidades comportamentais de representantes de cada classe, discussões a respeito de como o modelo de produção e consumo, que organiza as sociedades atuais, afeta diretamente as formas de relação com os animais, as aulas acerca da classificação, anatomia, fisiologia e ecologia de cada classe de vertebrados. Também foi realizada a exibição de dois documentários que chamam a atenção para a senciência dos animais não humanos, os direitos dos animais, as consequências dos modelos de uso e exploração adotados na pesquisa, no agronegócio e na indústria de maneira geral. Também foi desenvolvida a produção de um curta metragem no qual foi construído um recorte da realidade a partir da perspectiva do aluno e da aluna como síntese daquilo que permaneceu após a intervenção didática. Após todo esse processo, alunos e alunas foram novamente solicitados a discorrer sobre a frase "Fale sobre os animais. $E$ os animais em relação aos seres humanos", produzindo a narrativa final, a partir da qual foram identificados os três tipos de interpretantes dinâmicos.

\section{ANÁLISE DOS DADOS E DISCUSSÃO}

Abaixo estão apresentados, na sequência, os momentos narrativa inicial e final, onde em cada um se encontra a análise baseada nas categorias de interpretante do quadro 2. Devida a natural dificuldade de separar em uma narrativa uma dimensão interpretante única, tomou-se, por critério, definir a narrativa por um interpretante dinâmico mais dominante, visto que os mesmos se interpenetram em certos excertos. 


\section{Primeiro momento: Narrativa Inicial}

Os interpretantes emocionais nas narrativas iniciais são identificados a partir da evocação de palavras e/ou expressões que remetem à qualidade de sentimentos e emoções conforme os critérios do instrumento analítico proposto. Tais manifestações podem ser verificadas nos trechos a seguir:

\section{Morro de medo de aranha [...]. Aluna COM}

Tenho dois cachorros e gosto deles, são tão especiais, é um amor sincero [...]. Aluna YSS

Em nossa volta existem muitos animais diferentes que fazem parte das nossas vidas e nem nos damos conta da sua existência. Aluno CEF

Animais muitas vezes não se dão bem com humanos, porque os humanos sempre fazem o mal. Aluno ADA

Tais características são observadas quando os alunos e alunas dizem gostar, amar, ter medo, dó, raiva dos animais, assim como sentir amizade, rejeitar e entristecer-se diante de maus tratos. São sentimentos expressos sem o compromisso de justificá-los. Assim, alunos e alunas apenas manifestam suas sensações primeiras em relação aos animais não humanos, espontaneamente. Predominam as emoções positivas de empatia, simpatia, afeto, mas as negativas também são apontadas à medida que animais não humanos representam perigo e repugnância, ou até indiferença. São expressões das relações que ainda não se traduzem em ações ou argumentos que possam explicar as emoções envolvidas, mas são apenas sentidas.

Os interpretantes energéticos são identificados a partir de verbos e/ou palavras e/ou expressões que evocam qualidade de ação, conflito de ideias, esforço de entendimento, dúvida, questionamento, necessidade de posicionamento. Tais interpretantes ficam evidentes nos trechos a seguir: 
Eu fico muito triste quando vejo alguém maltratando os animais, porque eles sentem dor e sofrem igual a nós. Aluno EPP

Minha opinião sobre os animais é o seguinte: alguns eu não gosto por serem bravos e fedorentos, morderem, mas por outro lado amo os gatos e os cachorros [...] Aluna COM

Tem seres humanos que são piores que animais, ou agem pior. $O$ bom dos animais é que eles não mentem, não magoam e demonstram seus sentimentos. Aluna YSS

Tais características são observadas quando alunos e alunas atribuem particularidades humanas aos animais, associam a lealdade dos animais domésticos como retribuição ao tratamento que os donos lhes dispensam, associam o sofrimento dos animais aos maus tratos que recebem, preferem os animais em vez de humanos, rejeitam alguns animais em função de características consideradas repulsivas, associam a maldade humana contra os animais ao provocar fome, violência, abandono e morte, interferem na vida do animal tirando-o da rua e dispensando cuidados, e associam o comportamento do animal à inteligência.

Observamos que há um movimento na direção de entender e explicar as relações ao declarar os posicionamentos positivos ou negativos, e o confronto das diferentes possibilidades de relação. Os contrapontos propostos pelas alunas COM e YSS, por exemplo, indicam o caráter energético do interpretante à medida que propõem explicar o porquê de suas rejeições ou preferências com relação aos animais.

Os interpretantes lógicos são identificados nas narrativas iniciais a partir da presença de verbos, e/ou palavras, e/ou expressões que evocam qualidade de interpretação, de regras gerais, de posicionamento definido diante de um fato ou ideia, argumento acerca da sua concordância ou discordância diante de um fato ou ideia. Os fragmentos de fala a seguir apontam para esses interpretantes. 
Os animais são divididos em dois tipos, invertebrados e vertebrados. Aluno $A D A$

Os animais são classificados em peixes, anfíbios, répteis, aves e mamíferos que são os vertebrados. Aluno CEF

Sou contra manter animais em cativeiro, e não gosto de zoológico, pois nenhum animal merece viver preso num cubículo, eles foram feitos para viver livres [...] Aluna JCC

Existem diversas espécies de animais, muitos foram diagnosticados para facilitar muitos trabalhos no campo e melhorar a produtividade como, por exemplo, os cachorros utilizados como pastores de ovelhas. Aluno ASS

Tais manifestações são observadas na escrita daqueles alunos e alunas que percebem que ter a posse/tutoria de um animal exige responsabilidade para cuidar do mesmo, associam os cuidados com os animais a custos financeiros, identificam a dependência dos animais domésticos em relação aos humanos por ter perdido as características selvagens, distinguem os animais quanto à sua classificação biológica em vertebrados e invertebrados, associam a produção de medicamentos e a agricultura ao uso de animais que contribuem especificamente para esse fim, afirmam que os maus tratos a animais provocam dor e sofrimento similar aos sentidos pelos humanos, rejeitam a ideia de um zoológico em função das condições de vida às quais os animais são submetidos quando vivem nesses ambientes. Estas são generalizações que denotam posicionamentos já estabilizados pelos intérpretes.

A classificação biológica apontada pelos alunos CEF e ADA são regras interpretativas associadas ao conhecimento científico já aprendido e estabilizado. A colocação contundente da aluna JCC revela um posicionamento definido atrelado aos argumentos que sustentam tal posição, ao afirmar que o cativeiro não é bom para os animais. 


\section{Segundo momento: Narrativa Final}

Os Interpretantes emocionais que se evidenciam nas construções textuais dos alunos e alunas são observados nas mensagens a seguir:

Como é triste ver nosso Brasil pegando animais para fazer testes de produtos [...] isso dói [...] Eu amo os animais e é por isso que tenho 3 cachorros e um gato, mas eu preciso deles pra viver, o amor que eu tenho por eles só Deus sabe. Aluna COM

Os animais são muito bons, carinhosos, amorosos, companheiros, fofos, amigos, mas o ser humano trata os animais com diferença como se ele fosse melhor, mais importante [...]. Aluna KPS

Os animais são muito importantes pra nós, são animais, mas eles muitas vezes nos ajudam [...]. Aluno $A D A$

Os interpretantes ficam identificados a partir das evocações que apontam importância dos animais para os humanos, a consideração da possibilidade de boa relação entre humanos e animais, a valorização da existência dos animais, o entristecimento com contrabando de animais, surpresa e espanto com as ações humanas que causam mal aos animais, tristeza com a prática de testes em animais, o amor aos animais e a necessidade da companhia dos animais para viver. De forma geral, são expressões de uma sensibilidade que considera os animais como algo admirável e bom. Embora a aluna COM ter mencionado que tem três cães e precisa deles para viver, ela não avança no sentido de justificar essa necessidade, ou apontar quais as razões concretas que estão atreladas a essa afirmação. Mesmo no decorrer de toda a sua narrativa, a aluna não explicitou tais explicações, permanecendo caracterizado o interpretante emocional.

Os interpretantes energéticos como reações ativas dos estudantes, são identificados a partir de convocatórias à ação. Abaixo são apresentados alguns comentários seguidos das identificações desses interpretantes. 
Por que usarem os animais? Será que eles aceitariam estar no lugar deles? Acho que não [...] Às vezes deixamos os animais domésticos trancados, pensamos apenas em nós, no nosso viver, esquecemos que eles precisam de carinho. Aluno ADA

Uma coisa que precisa ser mudada nesse mundo é isso... Pra que tanta raiva? Pra que fazer os animais sofrerem? Eles não têm culpa de nada e muitos animais não são perigosos. Isso tem que mudar o quanto antes, pra mim isso é "crime". A pessoa que matar animais devia ir preso. Então, isso me fez refletir muito... assim como nós, os animais têm sentimento, têm amor, têm seus momentos de dor, solidão, tristeza, mas também eles tem uma "VIDA" [...]. Aluna MCO

Nós precisamos agir em defesa desses (animais) que precisam, sendo isso questão de respeito e ética, virtudes indispensáveis nos seres humanos e não humanos. Aluna DLF

Tais interpretantes estão relacionados ao questionamento, à problematização, ao confronto, ao sugerir o uso de humanos em testes, condicionar a boa relação entre humanos e animais ao respeito, relacionar a despreocupação com os animais ao interesse maior de ganhar dinheiro, convocar para a necessidade de agir em defesa dos animais, atribuir a proximidade com os animais ao crescimento das cidades, questionar os hábitos humanos que dependem do uso de animais, relacionar o estudo ao conhecimento dos animais, questionar o grau de valoração (de inferioridade) que os humanos atribuem aos animais não humanos, rejeitar canis, jaulas e gaiolas para manter animais fechados, além de recusar a prática de usar animais como cobaias. Nessas falas, observamos que há um nítido confronto dos sentimentos que os animais fazem brotar nos intérpretes e que foram identificados nos interpretantes emocionais acima examinados, e a não aceitação da crueldade, dos maus tratos dirigidos a seres considerados inocentes. Há um movimento, um esforço de compreensão, de rejeição diante das situações identificadas. A capacidade de questionar os modelos praticados pelos humanos e a ampliação da noção do que sejam maus tratos, são 
integrados pela experiência colateral. As provocações e debates propiciados pelas leituras, pelos vídeos e pela produção do vídeo de curta metragem, propiciaram uma nova familiaridade com a questão, que permitiu um olhar com novas referências construídas.

Já os interpretantes lógicos, como regra interpretativa, seguem identificados a partir dos seguintes trechos:

Os animais são seres humanos como nós, sentem dor, fome, tem liberdade de viver, se reproduzir, andar, tem liberdade como nós temos, pois não foram criados para ser cobaias de laboratório. Imagina colocar um filho nosso pra ser criado em gaiolas ou colocar uma mulher pra ser somente criadora de crianças. Isto não existe, não é correto, é estúpido, ridículo, tanto com um animal quanto com uma criança humana. Aluna ENT

Quando compramos um mísero produto como sapato, roupa e etc, estamos influenciando o maltrato aos animais, pois eles são submetidos a testes antes de aprovar alguns produtos nos seres humanos. [...] Nós certamente não damos o valor necessário para os animais, não levamos em conta a importância deles para nossa sobrevivência. Fazemos deles animais subjugados, e eles não têm a capacidade de escolha que nós temos. São totalmente submissos às necessidades humanas. Deveríamos ter mais conhecimento do que realmente acontece dentro de fábricas e laboratórios, ter um interesse e uma visão mais ampla de tudo o que ocorre [...]. Sem dúvida, nossa relação com os animais seria bem melhor. Aluna MEG

Afinal, animais não estão no mundo para nos servir, estão para que haja um equilíbrio biológico natural, e isso nós devemos respeitar [...] Aluno CEF

Tais comentários implicam interpretantes referentes à tomada de consciência com relação às formas de relação dos seres humanos com os animais, principalmente daquelas relações destrutivas, de exploração e que causam sofrimento. Afirmar que a existência dos animais serve para serem felizes e não usados, apontar que a exploração animal ocorre em função do desejo de lucro dos humanos, afirmar que animais não existem para servir 
humanos, mas sim para manter um equilíbrio biológico natural, considerar que o comportamento humano representa perigo para os animais não humanos, afirmar que a relação de superioridade com animais não humanos precisa mudar, associar a melhoria das relações com os animais não humanos à necessidade de conhecimento dos bastidores dos laboratórios que realizam testes, concluir que, se somos todos animais, os não humanos também são dignos de consideração, apontar para as campanhas educativas como forma de superar a violência contra os animais não humanos, são ideias centrais relacionadas aos interpretantes lógicos.

Mediante o sequenciamento didático e a utilização das análises dos interpretantes dinâmicos, possibilitou-se confrontar ideias originais advindas do senso comum dos estudantes com novas concepções e, com isso, fazer conexões entre o uso e a exploração de animais e as consequências éticas e ambientais dessas práticas. As categorias analíticas permitiram ver que os escolares, através de generalizações, conseguiram extrapolar, inclusive de forma coletiva pelas discussões, as situações nas quais as relações entre humanos e animais podem produzir consequências negativas. O quadro 3 sintetiza as principais ideias referentes a cada categoria interpretante dinâmico, expressos nas narrativas inicial e final produzidas pelos alunos e alunas acerca do Signo: "Fale sobre os animais. $E$ os animais em relação aos seres humanos". O quadro 3 ilustra a mudança do conhecimento relacional quando confrontamos os interpretantes de ambas as narrativas. Fica evidenciado que o teor das argumentações avançou na articulação das ideias com generalizações que abarcam uma percepção mais complexa da realidade.

Quadro 3 - Síntese dos interpretantes identificados nas narrativas.

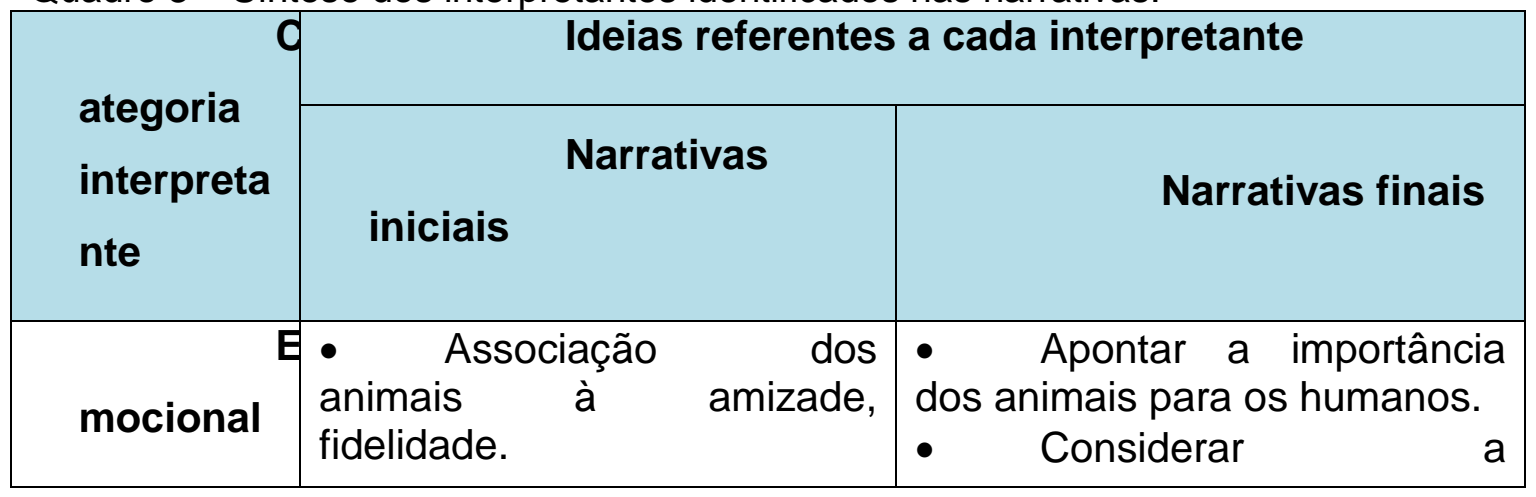




\begin{tabular}{|c|c|c|}
\hline & $\begin{array}{l}\text { - Gostar de animais. } \\
\text { - Não gostar de alguns } \\
\text { animais. } \\
\text { - Ter raiva de alguns } \\
\text { animais. } \\
\text { - } \quad \text { Ter dó dos animais. } \\
\text { - } \quad \text { Rejeitar a maldade e } \\
\text { os maus tratos. } \\
\text { - Ter medo de alguns } \\
\text { animais. } \\
\text { - Evocar o perigo que } \\
\text { alguns animais representam. } \\
\text { - Sentir tristeza diante } \\
\text { de maus tratos. } \\
\text { - Amar os animais. }\end{array}$ & $\begin{array}{l}\text { possibilidade de boa relação } \\
\text { entre humanos e animais. } \\
\text { - Valorizar a existência } \\
\text { dos animais. } \\
\text { - Entristecer-se } \\
\text { contrabando de animais. } \\
\text { - Surpreender-se com as } \\
\text { ações humanas que causam } \\
\text { mal aos animais. } \\
\text { - Entristecer-se com a } \\
\text { prática de testes em animais. } \\
\text { - Amar os animais. } \\
\text { - Necessitar } \\
\text { companhia dos animais para } \\
\text { viver. }\end{array}$ \\
\hline nergético & $\begin{array}{l}\text { - Atribuir características } \\
\text { humanas aos animais. } \\
\text { - Associar a lealdade } \\
\text { dos animais domésticos como } \\
\text { retribuição ao tratamento dos } \\
\text { donos. } \\
\text { - Associar o sofrimento } \\
\text { dos animais aos maus tratos } \\
\text { que recebem. } \\
\text { - Preferir os animais em } \\
\text { relação aos humanos. } \\
\text { - Rejeitar alguns animais } \\
\text { em função de características } \\
\text { consideradas repulsivas. } \\
\text { - Associar a maldade } \\
\text { humana contra os animais ao } \\
\text { provocar fome, violência, } \\
\text { abandono e morte. } \\
\text { - Interferir na vida do } \\
\text { animal tirando-o da rua e } \\
\text { dispensando cuidados. } \\
\text { - Associar } \\
\text { comportamento do animal à } \\
\text { inteligência. } \\
\text { - Atribuir o equilíbrio da } \\
\text { natureza à existência dos } \\
\text { animais. }\end{array}$ & $\begin{array}{l}\text { - Sugerir o uso de } \\
\text { humanos em testes. } \\
\text { - Condicionar a boa } \\
\text { relação entre humanos e } \\
\text { animais ao respeito. } \\
\text { - Relacionar } \\
\text { despreocupação com os } \\
\text { animais ao interesse maior de } \\
\text { ganhar dinheiro. } \\
\text { - Convocar para a } \\
\text { necessidade de agir em defesa } \\
\text { dos animais. } \\
\text { - Atribuir a proximidade } \\
\text { com os animais ao crescimento } \\
\text { das cidades. } \\
\text { - Questionar } \\
\text { humanos, os quais dependem } \\
\text { do uso de animais. } \\
\text { - Relacionar o estudo ao } \\
\text { conhecimento dos animais. } \\
\text { - Questionar o grau de } \\
\text { valoração que os humanos } \\
\text { atribuem aos animais. } \\
\text { - Rejeitar canis, jaulas e } \\
\text { gaiolas para manter animais } \\
\text { presos. } \\
\text { - Recusar a prática de } \\
\text { animais como cobaias. }\end{array}$ \\
\hline ógico & $\begin{array}{l}\text { - Perceber que ter a } \\
\text { posse/tutoria de um animal } \\
\text { exige responsabilidade. } \\
\text { - } \quad \text { Associar os cuidados }\end{array}$ & $\begin{array}{l}\text { - Afirmar que a existência } \\
\text { dos animais é para serem } \\
\text { felizes e não usados. } \\
\text { - Apontar que } \quad \text { a }\end{array}$ \\
\hline
\end{tabular}




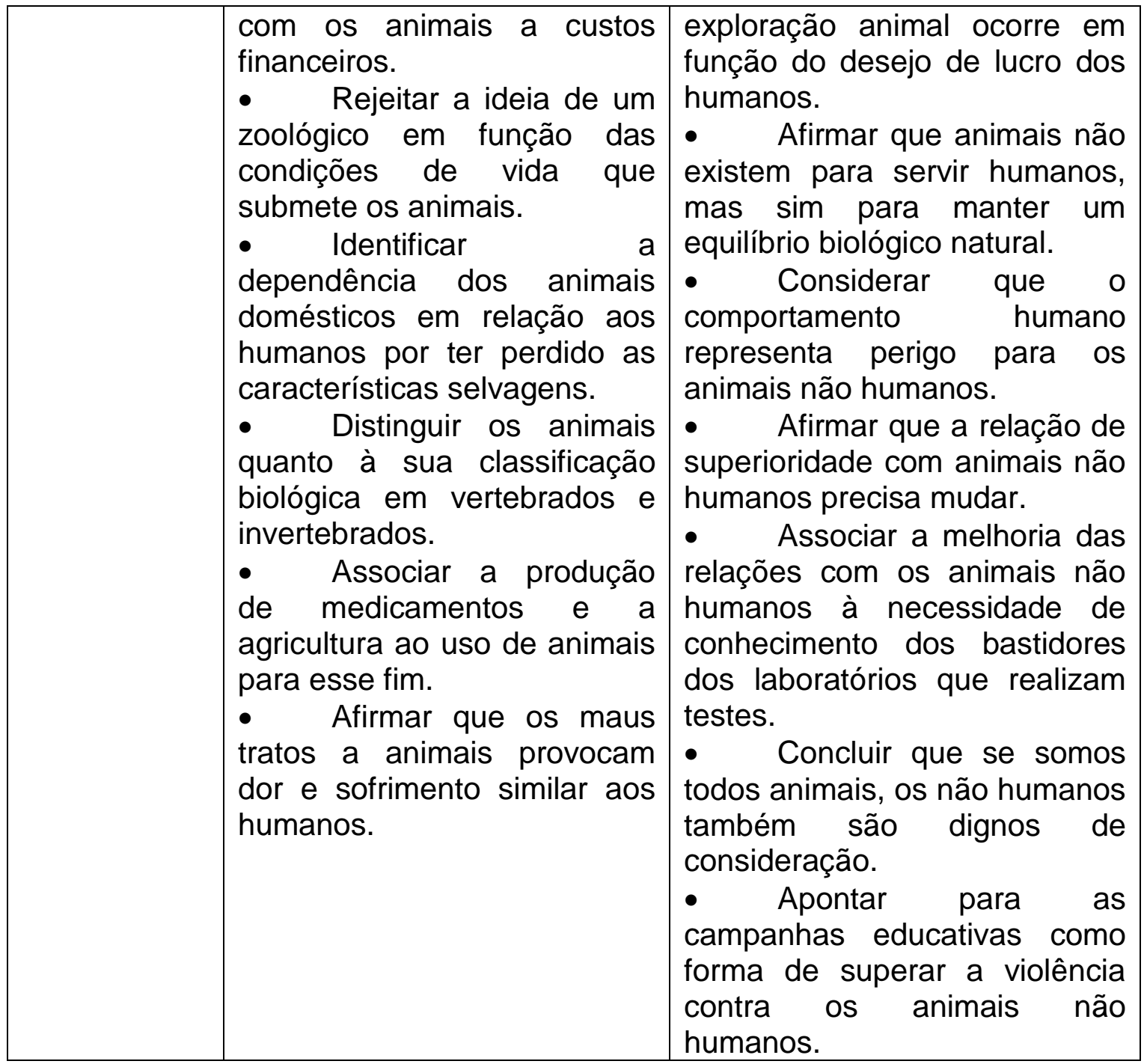

Fonte: os autores.

$\mathrm{Na}$ medida em que a narrativa final agrega elementos das formas de relação dos humanos com os animais não humanos, que antes não estavam presentes, se pode afirmar que o signo foi atualizado, e as experiências do senso comum no decurso da intervenção didática propiciaram ampliar o repertório dos estudantes para identificar e discutir o tema na produção de seu curta metragem. O olhar para o seu entorno não foi o mesmo do qual lançaram mão para escrever a narrativa inicial. $\mathrm{Na}$ escrita da narrativa final, $\mathrm{O}$ encadeamento das mensagens que mostram a desestabilização emocional, o questionamento de valores e práticas naturalizadas na sociedade, os posicionamentos contundentes acerca do tratamento com os animais, a 
proposição de atitudes e comportamentos foram observados em todos os alunos da amostra.

Nas narrativas iniciais predominam as descrições associadas aos animais domésticos como cães e gatos, classificações biológicas mais elementares como a distinção entre vertebrados e invertebrados e divisão das classes de vertebrados em peixes, anfíbios, répteis, aves e mamíferos. A partir de uma leitura geral das narrativas, evidenciam-se os elementos da experiência de senso comum, manifestas nas formas com que alunos e alunas descrevem situações vivenciadas com animais no seu cotidiano, com os animais domésticos com os quais convivem em suas casas ou em outros ambientes. Assim, o signo proposto pela questão da narrativa é constantemente ressignificado pelos alunos mediante a experiência de senso comum. Para tratar o tema, os estudantes recorreram com frequência a situações já vivenciadas com os animais que integram os pré-requisitos para acessar as ideias significadas pelo signo. O desenvolvimento da narrativa decorreu dos limites da experiência cotidiana de cada sujeito.

Portanto, a convivência com animais domésticos, por ser uma realidade para vários alunos envolvidos na pesquisa, auxiliou os interpretantes das narrativas finais a se voltarem muito mais para generalizações que aborcassem uma sensibilidade que ultrapassou o ambiente doméstico, evidenciando um esforço questionador das práticas hegemônicas sejam na pesquisa ou na indústria.

\section{CONSIDERAÇÕES FINAIS}

O problema deste estudo se propôs questionar a gama de entendimentos dos alunos e alunas do ensino médio acerca das relações dos seres humanos com os animais por meio de uma leitura dos interpretantes dinâmicos peirceanos no contexto de um ensino sobre vertebrados com abordagem ambiental. A ideia foi empregar a abordagem da tríade interpretante dinâmica para ver se ela tem potencial analítico de 
constatar se a compreensão dos aprendizes acerca das relações dos seres humanos com animais consegue avançar em relação ao senso comum.

Assim, partimos de uma intervenção didática na qual buscamos ensinar uma Biologia contextualizada, sem perder de vista a identidade da Biologia como disciplina das Ciências Naturais, atentando para que o relacional não tomasse o lugar dos conceitos científicos, ao mesmo tempo tentando superar a "letra fria" das propostas protocolares que reproduzem a legislação ou o conteúdo rígido.

O instrumento analítico dos interpretantes dinâmicos se mostraram frutíferos com elementos de escrutinação para identificar a complexificação da compreensão do conteúdo em foco. Ao olhar para as narrativas, compará-las, verificamos os avanços no âmbito do sentir, do agir e do pensar que as componentes do interpretante dinâmico permite.

O estudo mostrou que as categorias analíticas do interpretante dinâmico propostas foram apropriadas para a sondagem dos significados construídos por aprendizes quando o tema em estudo ultrapassa o simples conteúdo, próprio da componente lógica do interpretante dinâmico, e envolve, concomitantemente, dimensões do tipo energético e emocional. Com isso, o trabalho pode ser sugerido e estendido para ensinos em temáticas outras da educação científica que envolvam também as três dimensões e, com isso, instrumentalizar o professor com uma possibilidade analítica para acompanhar o desenvolvimento das ideias de seus estudantes.

Mais especificamente ao conteúdo aqui abordado, educacionalmente não se pode garantir que os indivíduos, na prática, alterem suas inércias de manifestações de simpatia pelos animais, ordenadas em uma escala de valor, geralmente inconsciente conforme Singer (1989 apud DESCOLA), mas totalmente explícita em alguns animais - "cujo ápice é ocupado pelas espécies percebidas como as mais próximas do homem em função de seu comportamento, fisiologia, faculdades cognitivas ou da capacidade que lhes é atribuída de sentir emoções" (DESCOLA, 1998, p. 23). Independentemente do meio em que vivem, notável é como os mamíferos 
são mais bem aquinhoados nessa hierarquia do interesse: "Ninguém, assim, parece se preocupar com a sorte dos arenques ou dos bacalhaus, mas os golfinhos, que com eles são por vezes arrastados pelas redes de pesca, são estritamente protegidos pelas convenções internacionais" (ibid.). Entretanto, educacionalmente pode-se aprimorar o estabelecimento de uma reflexão e tomada de consciência acerca do antropocentrismo, num contexto da capacidade de se identificar com animais não humanos em função de seu suposto grau de proximidade com a espécie humana, o que assim parece "constituir a tendência espontânea das diversas possibilidades ecológicas contemporâneas, inclusive aquelas que professam as teorias mais radicalmente anti-humanistas" (ibid.). Em síntese, compreendendo as formas e razões pelas quais um ser vivo venha se tornar comida ou é aproveitado pela natureza quando em deterioração, cabem as três perguntas levantadas por Descola (ibid., p. 32):

Como não reconhecer o estatuto ambíguo dos animais, especialmente dos mamíferos superiores, tão próximos de nós sob tantos aspectos e contudo tão diferentes? Quem nunca atribuiu, ainda que de maneira fugaz, emoções, uma sensibilidade, uma intencionalidade a um animal de estimação? O próprio sofrimento infligido às vezes aos animais não seria um sinal de que percebemos sua natureza como essencialmente equívoca, a meio caminho da humanidade e dos outros objetos do mundo, vivos ou não-vivos?

Por fim, a justa observação de Luc Ferry (apud DECOLA, 1998, p. 32), na qual, quer se tenha prazer ou não acerca do espetáculo do sofrimento de um animal, não pode nos deixar indiferentes, pois, "evocando o nosso, lembra-nos uma analogia fundamental que as plantas são incapazes de suscitar, mesmo com um grande esforço de imaginação". 


\section{REFERÊNCIAS}

ANDERSON, D. R. Peirce's horse: a sympathetic and semeiotic bond. In: McKENNA, E.; LIGHT, A. (Ed.). Animal pragmatism: rethinking humannonhuman relationships. Bloomington: Indiana University Press, p. 86-94, 2004.

BRÜGGER, P. Nós e os outros animais: especismo, veganismo e Educação Ambiental. Linhas Críticas, Brasília, v. 15, n. 29, p. 197-214, 2009.

CHIZZOTTI, A. A pesquisa qualitativa em ciências humanas e sociais: evolução e desafios. Revista Portuguesa de Educação, Braga, ano 16, v. 2c p. 221 236, 2003.

DESCOLA P. Estrutura ou Sentimento: a relação com o animal na Amazônia. MANA, 4 (1): 23-45, 1998.

EPSTEIN, I. O signo. São Paulo: Ática, 1985.

FIDALGO, A.; GRADIM, A. Manual de Semiótica. Portugal: UBI, 2004-2005.

FERREIRA, A. R.; LABURÚ, C. E. O admirável na educação ambiental e no ensino de biologia: o valor à vida é um summum bonun? $\mathrm{X}$ Congreso Internacional sobre Investigación en Didáctica de las Ciencias, Enseñanza de las Ciencias, n. Extraordinário, p. 3387-3392, 2017a.

FERREIRA, A. R.; LABURÚ, C. E. Os multimodos no ensino e aprendizagem de biologia com abordagem ambiental para os conteúdos de animais vertebrados. $X$ Congresso Internacional sobre Investigación en Dicáctica de las Ciencias, Enseñanza de las Ciencias, n. Extraordinário, p. 1367-1373, 2017b.

HART, P. Environmental Education. In: ABELL, S. K.; LEDERMAN, N. G. Handbook of research on Science education. New York, p. 689-728, 2012.

LEFF, E. (Coord.). A Complexidade ambiental. Tradução de Eliete Woff. São Paulo: Cortez, 2003.

LEFF, E. Saber ambiental: sustentabilidade, racionalidade, complexidade, poder. Petrópolis, RJ: Vozes, 2001.

PEIRCE, C. S. Obra filosófica reunida. Editores Nathan Houser e Christian Kloesel. Fundo de Cultura Econômica, 2012. t. 2 (1893-1913).

PEIRCE, C. S. Collected Papers. Cambridge: Harvard Univ. Press. 1978.

PEIRCE, C. S. Escritos Coligidos. São Paulo: Nova Cultural. 1989.

REIGOTA, M. A. dos S. Meio ambiente e representação social. 4 ed. São Paulo: Cortez, 2001a. 
REIGOTA, M. A. dos S. Verde cotidiano: o meio ambiente em discussão. 2 ed. Rio de Janeiro: DP\&A, 2001b.

SANTAELLA, L. Contribuições do pragmatismo de Peirce para o avanço do conhecimento. Revista de Filosofia, Curitiva, v. 16, n. 18, p. 75-86, 2004.

SANTAELLA, L. A eloquência das imagens dos vídeos de Educação Ambiental: uma análise semiótica. In: COSTA, L. B. da; TRAJBER, R. (Orgs.). Avaliando a Educação Ambiental no Brasil: materiais audiovisuais. São Paulo:

Peirópolis, 2001.

SHOOK, J. R. Os pioneiros do pragmatismo americano. Tradução. F. B. Said. Rio de Janeiro: DP\&A, 2002.

SOUZA, R. T. Ética e animais - reflexões desde o imperativo da alteridade. Veritas, Porto Alegre, v. 52, n. 2, p. 109-127, 2007.

SCHÖPKE, R. A psicopatia e os animais. In: DENIS, L. (Org.). Educação \& Direitos animais. São Paulo: Libra Três, 2014.

TURRISI, P. O papel do pragmatismo de Peirce na educação. Cognitio, São Paulo, v. 3, p. 122-135, 2002. 